\title{
Perspectives on Dermoscopy in the Primary Care Setting
}

\author{
Natalie M. Williams, BS, Ashfaq A. Marghoob, MD, Elizabeth Seiverling, MD, \\ Richard Usatine, MD, Darren Tsang, MD, MPH, and Natalia Jaimes, MD
}

Introduction: Dermoscopy is a noninvasive, in vivo imaging technique that allows for the visualization of subsurface skin structures. In recent years, several education interventions have incorporated dermoscopy in the primary care setting to improve skin cancer detection. We aim to describe the perspectives, attitudes, and interest of primary care physicians (PCPs) regarding dermoscopy.

Methods: PCPs associated with academic institutions completed an anonymous survey emailed to faculty and resident listservs. The survey consisted of 23 questions related to dermoscopy.

Results: A total of 156 PCPs completed the questionnaire. Few PCPs reported having access to a dermatoscope $(16 \%)$, using it regularly $(9 \%)$, or having received training $(15 \%)$. The most common reasons for not using a dermatoscope were the lack of access to the device $(85 \%)$, followed by the lack of training (76\%). However, the majority view dermoscopy as a valuable tool in primary care and are interested in receiving training $(87 \%)$, particularly with a hands-on approach.

Conclusion: Our sample of PCPs in the United States showed that although few use dermoscopy, most perceive it as a useful tool, particularly family medicine physicians. The main reported barriers preventing its use included the lack of training and poor access to dermatoscopes. The vast majority of PCPs in our sample want to be trained in dermoscopy, thereby providing an opportunity for educational initiatives that take into account the barriers and preferred learning strategies. $(\mathrm{J}$ Am Board Fam Med 2020;33:1022-1024.)

Keywords: Dermoscopy, Family Physicians, Primary Care Physicians, Primary Health Care, Skin Cancer, Surveys and Questionnaires

\section{Introduction}

Primary care physicians (PCPs) play a critical role in health care. PCPs encounter a variety of dermatologic diseases, including skin cancer. As skin cancer continues to be a public health problem, PCPs are imperative to early detection. Several educational

This article was externally peer reviewed.

Submitted 18 May 2020; revised 24 June 2020; accepted 8 July 2020.

From the Dr. Phillip Frost Department of Dermatology and Cutaneous Surgery, University of Miami Miller School of Medicine, Miami, FL (NMW, DT, NJ); Dermatology Service, Memorial Sloan-Kettering Cancer Center, New York, NY (AAM); Division of Dermatology, Maine Medical Center, Portland, ME (ES); Department of Family and Community Medicine, The University of Texas Health Science Center at San Antonio, San Antonio, TX (RU); Sylvester Comprehensive Cancer Center, Miami, FL (NJ).

Funding: None.

Conflict of interest: None.

Corresponding author: Natalia Jaimes, MD, Dr. Phillip Frost Department of Dermatology and Cutaneous Surgery, University of Miami Miller School of Medicine, Dermatology interventions provided to PCPs aim to improve skin cancer detection by incorporating dermoscopy.

Dermoscopy is a noninvasive technique that allows for the visualization of subsurface skin structures. Studies have demonstrated improved diagnostic accuracy for skin cancer when used by PCPs. ${ }^{1}$ In addition, mastery-learning courses in dermoscopy can improve diagnostic accuracy and increase physician confidence. As only $8 \%$ of PCPs in the United States use dermoscopy, ${ }^{2}$ there is opportunity to increase and promote its practice. However, before embarking on dermoscopy training initiatives, it is important to understand the views of PCPs in learning and implementing this tool.

\section{Methods}

In this Institutional Review Board-approved study, academic PCPs (family medicine, internal medicine,

Research Clinic, 1600 NW 10th Ave, RSMB 2023A, Miami, FL 33136, (E-mail: njaimes@med.miami.edu). 
Table 1. Participant Demographics and Career Information

\begin{tabular}{lc}
\hline Demographics & All No. $(\%)$ \\
\hline All & 156 \\
Gender & \\
Female & $98(62.8)$ \\
Male & $58(37.2)$ \\
Age, years & \\
25 to 34 & $83(53.2)$ \\
35 to 44 & $30(19.2)$ \\
45 to 54 & $20(12.8)$ \\
55 to 64 & $21(13.5)$ \\
65 to 74 & $2(1.3)$ \\
Specialty & \\
Family medicine & $67(42.9)$ \\
Internal medicine & $55(35.3)$ \\
Pediatrics & $27(17.3)$ \\
Med/peds & $7(4.5)$ \\
Years practiced & \\
Current resident & $81(51.9)$ \\
0 to 4 & $10(6.4)$ \\
5 to 14 & $19(12.2)$ \\
15 to 24 & $24(15.4)$ \\
25 to 34 & $15(9.6)$ \\
35 to 44 & $7(4.5)$ \\
Location & $117(75.0)$ \\
Urban & $33(21.2)$ \\
Suburban & $6(3.8)$ \\
Rural & \\
\hline & \\
& \\
&
\end{tabular}

pediatrics) associated with the University of Miami and Tufts University completed an anonymous survey emailed to faculty and resident listservs. Summary statistics and comparative analyses were performed using Statistical Analysis Software 9.4 (SAS Inc., Cary, NC). Categorical variables were analyzed using a Pearson's $\chi^{2}$ test and Fisher's exact test. All tests were 2 -tailed and $P<.05$ was considered statistically significant.

\section{Results}

Overall, 156 PCPs completed the questionnaire (Table 1). Over half of the respondents were residents. Of the participants, $16 \%$ reported having access to a dermatoscope, with only $9 \%$ regularly using it. Compared with residents, attendings were more likely to have access to a dermatoscope (27\% vs $6 \%, P=.0008)$ and to use it in their clinical practice (17\% vs $1 \%, P=.0004)$. A minority of respondents
Table 2. Participant Perspectives Regarding Dermoscopy

\begin{tabular}{|c|c|}
\hline Perspectives on Dermoscopy & $\begin{array}{l}\text { All No. } \\
(\%)\end{array}$ \\
\hline All & 156 \\
\hline \multicolumn{2}{|l|}{ Dermatoscope access } \\
\hline No & $131(84.0)$ \\
\hline Yes & $25(16.0)$ \\
\hline \multicolumn{2}{|l|}{ Dermatoscope use } \\
\hline No & $142(91.0)$ \\
\hline Yes & $14(9.0)$ \\
\hline \multicolumn{2}{|l|}{ Prior dermoscopy training } \\
\hline No & $133(85.3)$ \\
\hline Yes & $23(14.7)$ \\
\hline \multicolumn{2}{|l|}{$\begin{array}{l}\text { Importance of dermoscopy in primary } \\
\text { care }\end{array}$} \\
\hline Extremely important & $30(19.2)$ \\
\hline Very important & $37(23.7)$ \\
\hline Moderately important & $51(32.7)$ \\
\hline Slightly important & $30(19.2)$ \\
\hline Not at all important & $8(5.2)$ \\
\hline \multicolumn{2}{|l|}{ Reasons for not using a dermatoscope ${ }^{*}$} \\
\hline Lack of access to a dermatoscope & $116(85.3)$ \\
\hline Lack of training & $104(76.5)$ \\
\hline Cost of dermatoscope & $32(23.5)$ \\
\hline Time constraints & $32(23.5)$ \\
\hline Unlikely to have an impact & $10(7.4)$ \\
\hline \multicolumn{2}{|l|}{ Should PCPs receive dermoscopy training? } \\
\hline $\begin{array}{l}\text { Yes, should be provided during residency } \\
\text { (obligatory) }\end{array}$ & $83(55.0)$ \\
\hline $\begin{array}{l}\text { Yes, should be given during residency } \\
\text { (optional) }\end{array}$ & $48(31.8)$ \\
\hline Yes, once practicing (optional) & $13(8.6)$ \\
\hline No & $7(4.6)$ \\
\hline \multicolumn{2}{|l|}{ Interest in dermoscopy training } \\
\hline Very interested & $104(68.9)$ \\
\hline Somewhat interested & $27(17.9)$ \\
\hline Neutral & $7(4.6)$ \\
\hline Not very interested & $8(5.3)$ \\
\hline Not at all interested & $5(3.3)$ \\
\hline \multicolumn{2}{|l|}{ Preferred dermoscopy training } \\
\hline $\begin{array}{l}\text { Hands-on training (rotation, } \\
\text { observership) }\end{array}$ & $57(41.3)$ \\
\hline $\begin{array}{l}\text { Self study using dermoscopy textbook } \\
\text { and/or app }\end{array}$ & $34(25.4)$ \\
\hline In-person course (lecture style PowerPoint) & $17(13.6)$ \\
\hline Online video (lecture style) & $9(7.2)$ \\
\hline Web-based modules with self-paced learning & $10(7.8)$ \\
\hline \multicolumn{2}{|l|}{ Ideal duration for hands-on training } \\
\hline Days (mean \pm SD) & $3.2 \pm 4.4$ \\
\hline Hours (mean $\pm \mathrm{SD}$ ) & $5.4 \pm 5.3$ \\
\hline \multicolumn{2}{|l|}{ Ideal duration for in-person course } \\
\hline Days $($ mean \pm SD) & $2.4 \pm 2.6$ \\
\hline Hours (mean $\pm \mathrm{SD})$ & $4.5 \pm 4.8$ \\
\hline
\end{tabular}

Continued 
Table 2. Continued

\begin{tabular}{lc}
\hline Perspectives on Dermoscopy & $\begin{array}{c}\text { All No. } \\
(\%)\end{array}$ \\
\hline Ideal duration for online video & \\
$\quad$ Sessions (mean $\pm \mathrm{SD})$ & $3.3 \pm 3.3$ \\
Hours (mean $\pm \mathrm{SD})$ & $2.6 \pm 3.2$ \\
\hline
\end{tabular}

*Multiple response (e.g. "select all that apply") question. PCPs, primary care physicians; SD, standard deviation.

(15\%) had received prior training in dermoscopy, which was significantly associated with both dermatoscope access and use $(P<.0001)$.

Although the response rate was low (156/506, $31 \%)$, most PCPs view dermoscopy as a valuable tool in primary care, with $76 \%$ rating it as at least moderately important (Table 2). The most common reason for not using dermoscopy was the lack of access (85\%), followed by lack of training $(76 \%)$. The majority were interested in receiving dermoscopy training and supported the implementation of courses into their respective residencies. Family medicine physicians were significantly more likely to perceive dermoscopy as valuable $(P<.002)$, use dermoscopy $(P=.0008)$, receive training $(P=.0008)$, and express interest in training $(P=.0364)$ compared with other specialties.

When questioned regarding preferred methods of dermoscopy education, the most popular choice was hands-on training (41\%) followed by self study (25\%) using a textbook or application. Participants suggested an average of 4- to 6-hour courses spanned over 2 to 3 days for hands-on or in-person trainings. For online videos, respondents recommended a 2- to 3-hour course spanned over 3 to 4 sessions.

\section{Discussion}

Although not many PCPs use dermoscopy, most perceive it as a useful tool, particularly family medicine physicians. The main barriers preventing its use include the lack of training and access to dermatoscopes. The cost of these devices, which range between $\$ 300$ and $\$ 1500$, was not commonly reported as a barrier to their implementation in practice. PCPs would prefer hands-on training, which aligns with the preferences of dermatology residents. ${ }^{3}$ Since clinical trainings may not be feasible for all PCPs, it is important to note that there are several online resources for the identification of skin cancer (that is, https://dermoscopedia.org/, Triage Amalgamated Dermoscopic Algorithm $\left[\mathrm{TADA}^{4}\right.$ ). Studies evaluating TADA, which offers novice dermoscopists a starting point when approaching lesions of concern, were previously published in this journal. ${ }^{5}$

The major limitation of the study is the low response rate, which may be an indirect representation of the lack of interest but is not unexpected with an anonymous survey sent to the listserv of busy physicians. However, understanding the barriers and preferred learning strategies provides valuable information to guide educational initiatives and increase dermoscopy use among PCPs.

To see this article online, please go to: http://jabfm.org/content/ 33/6/1022.full.

\section{References}

1. Secker LJ, Buis PA, Bergman W, Kukutsch NA. Effect of a dermoscopy training course on the accuracy of primary care physicians in diagnosing pigmented lesions. Acta Derm Venereol 2017;97: 263-5.

2. Morris JB, Alfonso SV, Hernandez N, Fernández MI. Examining the factors associated with past and present dermoscopy use among family physicians. Dermatol Pract Concept 2017;7:63-70.

3. Chen YA, Rill J, Seiverling EV. Analysis of dermoscopy teaching modalities in United States dermatology residency programs. Dermatol Pract Concept 2017;7:38-43.

4. Jaimes N, Marghoob AA. Triage amalgamated dermoscopic algorithm. J Am Acad Dermatol 2020;82: 1551-2.

5. Seiverling EV, Ahrns HT, Greene A, et al. Teaching benign skin lesions as a strategy to improve the Triage Amalgamated Dermoscopic Algorithm (TADA). J Am Board Fam Med 2019;32:96-102. 